\title{
Asymmetric Behavior of Inflation Uncertainty and Friedman-Ball Hypothesis: Evidence from Pakistan
}

\author{
Syed Kumail Abbas Rizvi* and Bushra Naqvi**
}

\begin{abstract}
This paper is a first attempt to measure and analyze inflation uncertainty in Pakistan. It makes several contributions to the literature. In the first stage, using quarterly data from 1976:01 to 2008:02, we model inflation uncertainty as a time varying process using the GARCH framework. In the second stage, we analyze the asymmetric behavior of inflation uncertainty using the GJR-GARCH and EGARCH models. For further analysis of asymmetry and leverage effects, we develop news impact curves as proposed by Pagan and Schwart (1990). Finally we investigate the causality and its direction between inflation and inflation uncertainty by using the bivariate Granger-Causality test to determine which inflation uncertainty hypothesis (Friedman-Ball or Cukierman-Meltzer) holds true for Pakistani data. We obtain two important results. First, the GJR-GARCH and EGARCH models are more successful in capturing inflation uncertainty and its asymmetric behavior than the simple GARCH model. This can also be seen from news impact curves showing a significant level of asymmetry. Second, there is strong evidence that the Friedman-Ball inflation uncertainty hypothesis holds true for Pakistan.
\end{abstract}

Keywords: Inflation, uncertainty, GJR-GARCH, EGARCH, Friedman-Ball hypothesis, Pakistan.

JEL Classification: C22, E31, E37.

\section{Introduction}

Inflation is one of the most largely observed and tested economic variables both theoretically and empirically. Its causes, impacts on other economic variables, and cost to the overall economy are well known and understood. One cannot say with certainty whether inflation is good or bad for an economy but if the debate focuses on inflation uncertainty or inflation variability instead of just inflation, economists generally agree

\footnotetext{
* 3rd Year Doctoral Student, CES - Axe Finance, Université Paris 1 Panthéon Sorbonne.

${ }^{* *} 2^{\text {nd }}$ Year Doctoral Student, CES - Axe Finance, Université Paris 1 Panthéon Sorbonne.
} 
on its negative impact on some of the most important economic variables—such as output and growth rate-via different channels.

Inflation uncertainty is considered one of the major costs of inflation since it not only distorts decisions regarding future saving and investment due to lower predictability of the real value of future nominal payments, but it also extends the adverse affects of these distortions to the efficiency of resource allocation and the level of real activity (Fischer 1981, Golob 1993, Holland 1993b).

One can divide the consequences of inflation uncertainty into two categories, ex-ante consequences and ex-post consequences. Ex-ante consequences are based primarily on decisions in which an economic agent rationally anticipates future inflation and its transmission can be performed via three different channels. The first channel is financial markets, where inflation uncertainty makes investment in long-term debt riskier, which increases expected returns and long-term interest rates. High long-term interest rates reduce investment in both the business and household sector via a fall in investment in plants and equipment and housing and durable goods. The second channel is through decision variables, where inflation uncertainty leads to uncertainty about the interest rate and other economic variables, due to which economic agents are unable to index contractual payments according to inflation, which in turn increases uncertainty about wages, rent, taxes, depreciation, and profits. Firms are thus forced to delay their hiring, production, and investment because these decisions are unlikely to be reversed, thus reducing the overall economic activity. The third channel is that of productive vs. protective strategies, through which inflation uncertainty forces firms to shift their allocation of resources from more productive to less productive uses such as improved forecasts about inflation and hedging activities via derivatives to cop up increased uncertainty. The firm's resources are diverted from productive strategies to protective actions, which are more costly for small enterprises and households (Golob, 1994). Ex-post effects of inflation uncertainty include the transfer of wealth due to the under- or overvaluation of real payments versus nominal payments, which disturbs the status quo between employer and employee, and lender and borrower (Blanchard, 1997).

However, the relationship between inflation and inflation uncertainty is debatable as it is still unclear whether high inflation causes uncertainty or uncertainty causes high inflation. Friedman (1977) was the first to formalize the relationship between inflation and inflation uncertainty and he strongly supported the causality running from 
inflation to inflation uncertainty, generally known as the Friedman-Ball hypothesis. This hypothesis has also been extensively studied and the overall results are mixed. Ball and Cecchetti (1990), Cukierman and Wachtel (1979), Evans (1991), and Grier and Perry (1998), among others, provide evidence in support of a positive impact of the average rate of inflation on inflation uncertainty. Grier and Perry (1998) find that, in all G7 countries, inflation has a significant and positive effect on inflation uncertainty. Hafer (1985) also tested Friedman's hypothesis that high inflation uncertainty leads to higher unemployment, lower output, and slower growth in employment by considering the standard deviation of quarterly inflation forecasts obtained through the ASA-NBER survey of professional forecasters as a proxy for inflation uncertainty.

On the other hand, the causality running in the opposite direction, from inflation uncertainty to inflation, is considered the CukiermanMeltzer hypothesis (Cukierman-Meltzer, 1986; Holland, 1995). There is some evidence in support of this hypotheses, including Baillie et al. (1996) for the UK, Argentina, Brazil, and Israel, and Grier and Perry (1998) for Japan and France.

There is also a debate on the origins of inflation uncertainty. One school of thought believes that monetary policy plays an important role in determining inflation uncertainty since it stems from the uncertainty of the monetary policy regime, known as "regime uncertainty." According to Ball (1990), when there is high inflation, policymakers face a dilemma: on one hand, they would like to reduce inflation, on the other hand, they fear that it will trigger a recession in the economy. Because the public is unaware of the inclination of policymakers, it will remain highly uncertain of the future course of inflation (Ball, 1992; Okun, 1971; Friedman, 1977). This uncertainty increases further due to the announcement of unrealistic stabilization programs by governments when there is a surge of high inflation (Fischer and Modigliani 1978). The second school of thought believes that inflation uncertainty arises because of the unknown magnitude of a change in price level due to a given change in money supply (Holland, 1993a).

The first objective of this study is to model inflation uncertainty for Pakistan. We focus on what should be a suitable proxy for inflation uncertainty. The most common way to estimate inflation uncertainty is through surveys of expectations, such as the Livingston survey in the US. Given point estimates of inflation forecasts obtained from different individual forecasters, we can proxy inflation uncertainty as a variance of inflation forecasts across cross sectional data. However, in his remarkable 
contribution, Engle (1983) first modeled inflation uncertainty as autoregressive or time varying conditional hetersoscedasticity $(\mathrm{ARCH})$, in which he used a conventional inflation equation with fixed parameters but allowed the conditional variance of inflation shocks (forecast errors) to vary over time, suggesting that this variance could be used as a proxy for inflation uncertainty.

Empirical research on the ARCH model often identifies long lag processes for the squared residuals, showing the persistent effects of shocks on inflation uncertainty. To model this persistence, many researchers subsequently suggested variations or extensions to the simple $\mathrm{ARCH}$ model to test the inflation uncertainty hypothesis. Bollerslev (1986) and Taylor (1986) independently developed the generalized ARCH $(\mathrm{GARCH})$ model, in which conditional variance is a function of the lagged values of forecast error and the conditional variance. Beside Bollerslev (1986), there are several studies which have modeled inflation uncertainty through GARCH frameworks, such as Bruner and Hess (1993) for US CPI data, Joyce (1995) for UK retail prices, Della Mea and Peña (1996) for Uruguay, Corporal and McKiernan (1997) for the annualized US inflation rate, Grier and Perry (1998) for G-7 countries, Grier and Grier (1998) for Mexican inflation, Magendzo (1998) for inflation in Chile, Fountas et al. (2000) for G-7 countries, and Kontonikas (2004) for the UK. All these studies modeled have inflation uncertainty through the GARCH model in some way.

The major drawback of the ARCH or GARCH models is that both models assume the symmetric response of conditional variance (uncertainty) to positive and negative shocks. However, it has been argued that the behavior of inflation uncertainty is asymmetric rather than symmetric. Brunner and Hess (1993), Joyce (1995), Fountas et al. (2006), and Bordes et al. (2007) are of the view that positive inflation shocks increase inflation uncertainty more than negative inflation shocks of equal magnitude. If this is correct, the symmetric ARCH and GARCH models might provide misleading estimates of inflation uncertainty (Crawford and Kasumovich, 1996). The three most commonly used GARCH formulations to capture the asymmetric behavior of conditional variance, are the GJR or threshold GARCH (TGARCH) models of Glosten, Jagannathan, and Runkle (1993) and Zakoïan (1994), the asymmetric GARCH (AGARCH) model of Engle and $\mathrm{Ng}$ (1993), and the exponential GARCH (EGARCH) model of Nelson (1991). 
The second objective of this study is to model and analyze the asymmetric behavior of inflation uncertainty in Pakistan, if it exists. We use the GRJ-GARCH and EGARCH models to capture leverage effects and also estimate the "news impact curve" for further analysis of the asymmetric behavior of inflation uncertainty.

The third objective of this study is to determine causality and its direction between inflation and inflation uncertainty, using the bivariate Granger causality test. This is carried out to determine which inflation uncertainty hypothesis (Friedman-Ball or Cukierman-Meltzer) holds for Pakistani data. We follow the two-step procedure suggested by Grier and Perry (1998), in which they first estimate conditional variance by GARCH and component GARCH methods and then conduct the Granger causality test between these conditional variances and the inflation series.

This paper is a first attempt to measure and analyze inflation uncertainty in Pakistan and it makes several contributions to the literature. We model inflation uncertainty as time varying conditional variance through the GARCH framework. Following Fountas and Karanasos (2007) and Bordes and Maveyraud (2008), we also extract inflation uncertainty using the GJR-GARCH (TGARCH) and EGARCH models to analyze and capture the asymmetric behavior of inflation uncertainty (leverage effects), if it exists. We also present "news impact curves" as proposed by Pagan and Schwart (1990) for different GARCH models to estimate the degree of asymmetry of volatility to positive and negative shocks of previous periods. Finally, we test the Friedman-Ball and Cukierman-Meltzer inflation uncertainty hypotheses using the bivariate Granger causality test.

The paper is organized as follows: A description of the data and preliminary analysis of time series is provided in Section 2; Section 3 presents the theoretical framework; Section 4 provides estimation and results. Section 5 concludes the study.

\section{Description and Preliminary Analysis of Data}

\subsection{Data Set}

Data availability and authenticity of available data are among the major hurdles one faces when working on Pakistan. There are two possible sources of data with reference to Pakistan: internal sources, which include the State Bank of Pakistan and the Federal Bureau of Statistics, and external sources, which include the IMF, World Bank, and other databases. For this 
paper, we have taken all data from the IMF's International Financial Statistics database due to its relatively broader coverage of different time series variables. The following variables are included in our data set.

Table-1: Variables Used

\begin{tabular}{ll}
\hline DATA & IFS Series \\
\hline CPI & ifs:s56464000zfq \\
GDP (Nominal) & ifs:s56499b00zfa \\
GDP Deflator & ifs:s56499bipzfa \\
M2 & ifs:s56435100zfq \\
\hline
\end{tabular}

Our sample ranges from 1976:1 to 2008:2. We use quarterly data because of its additional relevance and usability in the context of inflation in less developed countries as observed by Ryan and Milne (1994) and calculated quarterly growth rates on a Year-on-Year (Y-O-Y) basis for different variables by taking the fourth lagged difference of their natural logarithms. In other words, we calculate the percentage change in the concerned variable with its value from the corresponding quarter in the previous year.

Quarterly Growth Rate of $\mathrm{Y}_{t}$ on Year - on - Year Basis $=\ln \mathrm{Y}_{t}-\ln \mathrm{Y}_{t-4}$

Where $t$ represents Number of Quarters of Each Year

There are several advantages to using this method for the calculation of growth rates as compared to traditional annualized Quarter-on-Quarter (Q-o-Q) growth rates. Most importantly, growth rates calculated on a Y-o-Y basis are implicitly seasonally adjusted as each quarter is compared with the corresponding quarter in the previous year, thus growth rates not only show the underlying trend but remain sensitive to irregular shocks as well as capable of capturing deviations from expected seasonal behavior (Cheem, 2003).

Four different types of price indicators are available in Pakistan: the consumer price index (CPI), wholesale price index (WPI), sensitive price index SPI), and GDP deflator. For our analysis, we choose the CPI as it represents the cost of living in Pakistan more accurately and because it has been regularly updated in its composition and calculations (Bokhari and Faridun, 2006). 


\subsection{Descriptive Statistics of Data}

Using quarterly CPI data obtained from IFS, we calculate quarterly inflation on a Y-o-Y basis. Figure 1 shows clearly that inflation in Pakistan has been constantly high (above 5 percent) except for a very short period between 1982 and 1984, and 1999 and 2003. There is also a clear increasing trend in inflation from 2003 onward, which becomes extremely sharp near the end of our sample (2008Q2).

\section{Figure 1: Graphical Representation of Inflation, M2 Growth and Real} GDP Growth

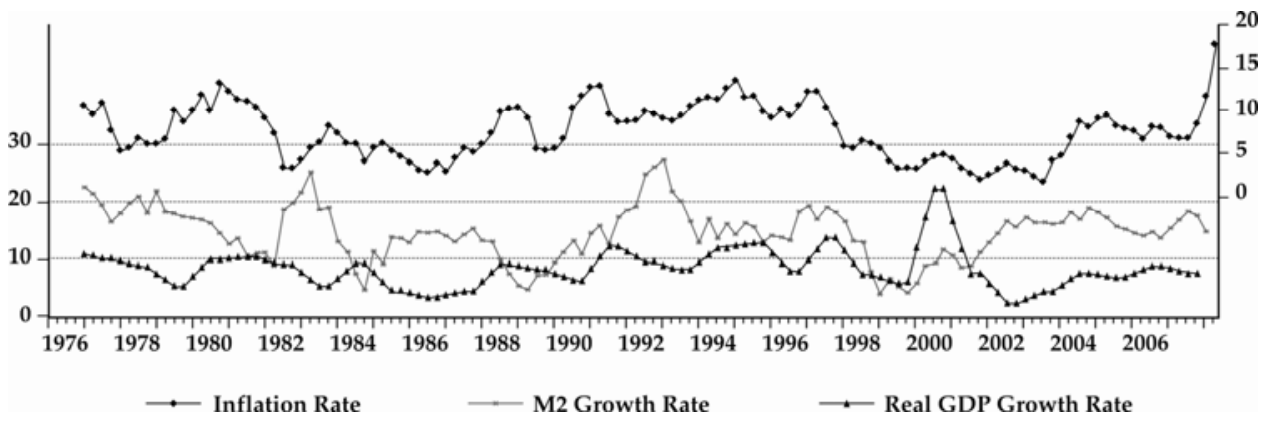

Table-2 provides descriptive statistics of the variables concerned, showing high variability in all three variables, despite the implicit smoothing built into the calculation of Y-o-Y rates. We are unable to reject the null of normality under Jarque-Bera statistics for inflation and the M2 growth rate, but we can reject the same for RGDP growth with high significance. The non-normal distribution of RGDP growth is also evident from the values of its skewness and kurtosis, which are higher than the normal benchmarks of 0 and 3 , respectively. 
Table-2: Descriptive Statistics of Variables

\begin{tabular}{lccc}
\hline & INFLATION & M2_GROWTH & RGDP_GROWTH \\
\hline Mean & 7.54 & 14.62 & 8.41 \\
Median & 7.41 & 14.78 & 8.17 \\
Maximum & 17.69 & 27.25 & 22.23 \\
Minimum & 1.76 & 3.93 & 2.43 \\
Std. Dev. & 3.13 & 4.66 & 3.32 \\
Skewness & 0.23 & -0.14 & 1.23 \\
Kurtosis & 2.52 & 3.08 & 6.64 \\
Jarque-Bera & 2.30 & 0.42 & 99.62 \\
Probability & 0.32 & 0.81 & 0.00 \\
Observations & 126 & 125 & 124 \\
\hline
\end{tabular}

\subsection{Stationarity of Variables and Preliminary Cointegration Analysis}

To check the order of integration in the considered time series, we conduct unit root tests in this section. The Augmented Dickey-Fuller (ADF) and Phillips-Perron (PP) tests were used and the results (Table 3) show that inflation is seriously affected by the problem of unit roots, and is thus nonstationary. On the other hand, for M2 growth, we have strong evidence rejecting the presence of the unit root, forcing us to believe its behavior to be stationary. The values of the Durbin-Watson statistic also strengthen our conclusion about the stationarity of M2 growth. However, the results for real GDP growth are somewhat ambivalent. The ADF test clearly rejects the possibility of its stationarity, showing strong presence of the unit root. However, the Phillips-Perron test rejects the null of the unit root at $10 \%$ and $5 \%$ but this rejection is questionable due to the low values of the Durbin-Watson statistics, pointing to the possible deterioration of results due to serial correlation. Interestingly, if we rely on the Kwiatkowski-Phillips-Schmidt-Shin (KPSS) test to check the stationarity of inflation, M2 growth, and real GDP growth, we do not have enough evidence to reject the null hypotheses of stationarity for all variables (results not reported), which is contradictory to the results of the ADF and PP tests for inflation and real GDP growth. 
Table-3: Unit Root Testing

\begin{tabular}{|c|c|c|c|c|c|c|}
\hline INFLATION & Statistic & Prob & $\begin{array}{c}\text { Lags/ } \\
\text { BW }\end{array}$ & AIC & SIC & DW Stats \\
\hline ADF (constant term) & -1.52 & 0.52 & $4(\mathrm{SIC})$ & 3.40 & 3.54 & 1.79 \\
\hline ADF (constant, trend) & -1.37 & 0.86 & $4(\mathrm{SIC})$ & 3.41 & 3.58 & 1.80 \\
\hline $\begin{array}{l}\text { PHILLIPS PERRON } \\
\text { (constant term) }\end{array}$ & -2.20 & 0.21 & 6 & 3.60 & 3.65 & 1.34 \\
\hline $\begin{array}{l}\text { PHILLIPS PERRON } \\
\text { (constant, trend) }\end{array}$ & -1.92 & 0.64 & 7 & 3.61 & 3.67 & 1.36 \\
\hline MONEY GROWTH & Statistic & Prob & $\begin{array}{c}\text { Lags/ } \\
\text { BW }\end{array}$ & AIC & SIC & DW Stats \\
\hline $\mathrm{ADF}$ (constant term) & -3.56 & 0.01 & $4(\mathrm{SIC})$ & 4.47 & 4.61 & 2.01 \\
\hline ADF (constant, trend) & -3.55 & 0.04 & $4(\mathrm{SIC})$ & 4.49 & 4.65 & 2.01 \\
\hline $\begin{array}{l}\text { PHILLIPS PERRON } \\
\text { (constant term) }\end{array}$ & -3.34 & 0.01 & 1 & 4.62 & 4.67 & 2.01 \\
\hline $\begin{array}{l}\text { PHILLIPS PERRON } \\
\text { (constant, trend) }\end{array}$ & -3.29 & 0.07 & 1 & 4.64 & 4.71 & 2.01 \\
\hline RGDP GROWTH & Statistic & Prob & $\begin{array}{c}\text { Lags/ } \\
\text { BW }\end{array}$ & AIC & SIC & DW Stats \\
\hline ADF (constant term) & -2.46 & 0.13 & $6(\mathrm{SIC})$ & 2.37 & 2.56 & 1.94 \\
\hline ADF (constant, trend) & -2.48 & 0.34 & $6(\mathrm{SIC})$ & 2.39 & 2.60 & 1.94 \\
\hline $\begin{array}{l}\text { PHILLIPS PERRON } \\
\text { (constant term) }\end{array}$ & -3.30 & 0.02 & 6 & 3.62 & 3.67 & 0.66 \\
\hline $\begin{array}{l}\text { PHILLIPS PERRON } \\
\text { (constant, trend) }\end{array}$ & -3.30 & 0.07 & 6 & 3.64 & 3.71 & 0.66 \\
\hline
\end{tabular}

Note: $* * * * *, *$ respectively indicates rejection of the null at $1 \%, 5 \%$ and $10 \%$ significance levels.

The above mentioned results prompt us to conduct a cointegration test, under the assumption of I(1) covariance stationarity of all variables to estimate any long-run relationship among them. 
Table-4: Johansen Cointegration Test for $\pi, M 2 G$ and $R G$

\begin{tabular}{lcccccc}
\hline $\begin{array}{l}\text { No. of } \\
\begin{array}{l}\text { Cointegrating } \\
\text { Vectors under } \\
\text { the Null }\end{array}\end{array}$ & \multicolumn{3}{c}{ Trace Test } & \multicolumn{4}{c}{ Maximum Eigenvalue Test } \\
\cline { 2 - 7 } Hypothesis & $\lambda_{\text {trace }}$ & $\begin{array}{c}\mathbf{5 \%} \text { Critical } \\
\text { Value }\end{array}$ & Prob. & $\lambda_{\text {max }}$ & $\begin{array}{c}\text { 5\% Critical } \\
\text { Value }\end{array}$ & Prob. \\
\hline None & 44.54 & 35.19 & 0.0037 & 22.67 & 22.30 & 0.04 \\
At most 1 & 21.87 & 20.26 & 0.03 & 18.04 & 15.89 & 0.02 \\
At most 2 & 3.83 & 9.16 & 0.44 & 3.83 & 9.16 & 0.44 \\
\hline
\end{tabular}

The Johansen test statistics (Table 4) reject the null hypothesis of no cointegrating vectors under both the trace and maximal eigenvalue forms of the test. Moving on to test the null of at most one cointegrating vector, the trace statistic is 21.87 , while the $5 \%$ critical value is 20.26 , so the null is just rejected at $5 \%$ (and not at $1 \%$ ). Finally, examining the null that there are at most two cointegrating vectors, the trace statistic is now well below the $5 \%$ critical value, suggesting that the null should not be rejected, i.e., there are at most two cointegrating vectors $(1 \leq r \leq 2)$.

We also apply Engle-Granger (EG) approach to testing the cointegrating relationship among variables, according to which the equilibrium errors of the cointegrating regression must be stationary for the variables to be cointegrated in the long run.

$$
\pi_{t}=\lambda+\theta M 2 G_{t}+\varphi R G_{t}+\varepsilon_{t}
$$

The estimated long-run coefficients of $M 2 G_{t}$ and $R G_{t}$ calculated from Equation 1 are reported in Table-5. 
Table-5: Regression Results of Equation (1)

\begin{tabular}{ll}
\hline Variables & Coefficients \\
\hline Constant & $2.116^{* *}$ \\
M2 growth rate $(M 2 G)$ & $0.168^{* * *}$ \\
Real GDP growth rate $(R G)$ & $0.339^{* * *}$ \\
Adjusted R-Square & 0.183 \\
D-W stat & 0.286 \\
Akaike info criterion & 4.86 \\
Schwartz info criterion & 4.924 \\
F-statistics & $14.79^{* * *}$ \\
\hline
\end{tabular}

Note: $* * * * * * *$ respectively indicates rejection of the null at $1 \%, 5 \%$ and $10 \%$ significance levels.

Unit root tests of $\varepsilon_{t}$, obtained from Equation 1 are given in Table6 , indicating that the residuals of the cointegrating regression are $\mathrm{I}(0)$ according to the ADF and PP tests at $10 \%$ and 5\%, respectively. However, we cannot reject the presence of the unit root in the residuals of the cointegrating regression if we introduce a trend term.

Table-6: Unit Root Test for Residuals of Cointegrating Regression

\begin{tabular}{lc}
\hline & Statistic \\
\hline ADF (constant) & $-2.61^{*}$ \\
ADF (constant, trend) & -2.71 \\
PHILLIPS PERRON (constant) & $-3.03^{* *}$ \\
PHILLIPS PERRON (constant, trend) & -3.02 \\
\hline
\end{tabular}

Note: ${ }^{* * *},{ }^{* *}, *$ respectively indicates rejection of the null at $1 \%, 5 \%$ and $10 \%$ significance levels.

\section{Inflation Uncertainty Framework}

In this section, we discuss the ARCH model and its extensions (GARCH, asymmetric GARCH [AGARCH], threshold GARCH [TGARCH], and exponential GARCH [EGARCH]) to analyze the relationship between inflation and inflation uncertainty. The formal presentation of the ARCH(q) model given by Engel (1982) is: 


$$
\begin{aligned}
& \pi_{t} \mid \psi_{t-1} \sim N\left(\kappa X_{t-1}, h_{t}\right) \\
& E_{t-1} \varepsilon_{t}^{2}=h_{t}=\alpha_{o}+\sum_{i=1}^{q} \alpha_{i} \varepsilon_{t-i}^{2}
\end{aligned}
$$

Equation 2 represents the conditional mean of inflation at time t, which depends on the information set at time period $t-1\left(\psi_{t-1}\right)$. Equation 3 is the conditional variance of unanticipated shocks to inflation which is equal to $\varepsilon_{t}=\pi_{t}-\kappa X_{t-1}$ and is actually the expected value of conditional variance at time $\mathrm{t}-1$, conditioned on the information set available at time t-1.

If $\alpha_{1}=\alpha_{2}=\alpha_{3}=\alpha_{q}=0$ then the conditional variance of errors is constant. However, to allow conditional variance as a time varying measure of inflation uncertainty (presence of $\mathrm{ARCH}$ ), at least one of the $\alpha_{i} \geq 0$ where $(i=1,2, \ldots \ldots, q)$. By applying the restriction $\sum_{i=1}^{q} \alpha_{i}<1$ we ensure that the ARCH process is covariance stationary. The non-negativity of all $\mathrm{ARCH}$ parameters $\alpha_{i}$ is a sufficient but not necessary condition to ensure that the conditional variance does not become negative.

However, evidence of long lag processes of squared residuals in the ARCH model suggest that shocks have persistence affects on inflation uncertainty, thus Bollerslev (1986) and Taylor (1986) independently suggest the alternative GARCH approach to modeling persistence, according to which the linear GARCH (p, q) process in Equation 4 represents the conditional variance of inflation forecast error, which is a function of the lagged values of both one-period forecast error and the conditional variance.

$$
\begin{aligned}
& h_{t}=\alpha_{o}+\sum_{i=1}^{q} \alpha_{i} \varepsilon_{t-i}^{2}+\sum_{j=1}^{p} \beta_{j} h_{t-j} \\
& \text { Where } \alpha_{\mathrm{o}}>0, \alpha_{\mathrm{i}} \geq 0 \text { and } \mathrm{i}=1,2, \ldots \ldots, \mathrm{q} \\
& \beta_{\mathrm{j}} \geq 0 \text { and } \mathrm{j}=1,2, \ldots \ldots, \mathrm{p}
\end{aligned}
$$

GARCH is more economical than $\mathrm{ARCH}$ as it has only three parameters and allows an infinite number of past squared errors to influence the current conditional variance (Brooks, 2002). It is also less likely to breach nonnegativity constraints, but the primary restriction of GARCH is that it enforces a symmetric response of volatility to positive and negative shocks. According to Brunner and Hess (1993) and Joyce (1995), a positive inflation shock is more likely to increase inflation uncertainty via the monetary policy mechanism, as compared to a negative inflation shock of equal size. If this is true, then we cannot rely on estimates of the symmetric ARCH and GARCH models and will have to go for the 
asymmetric GARCH models. Two popular asymmetric formulations are the GJR model and the EGARCH model proposed by Nelson (1991).

GJR-GARCH is simply an extension of GARCH (p, q) with an additional term to capture possible asymmetries (leverage effects). The conditional variance is now

$$
h_{t}=\alpha_{o}+\alpha_{1} \varepsilon_{t-1}^{2}+\beta_{1} h_{t-1}+\gamma \varepsilon_{t-1}^{2} I_{t-1}
$$

Where $I_{t-1}=1$, if $\varepsilon_{t-1}<0$, otherwise $I_{t-1}=0$. If the asymmetry parameter $\gamma$ is negative then negative inflationary shocks result in the reduction of inflation uncertainty (Bordes et al. 2007).

There are various ways of expressing the conditional variance equation, but one possible specification is

$$
\log h_{t}=\alpha_{o}+\sum_{j=1}^{q} \beta_{j} \log h_{t-j}+\sum_{i=1}^{p} \alpha_{i}\left|\frac{\varepsilon_{t-i}}{\sqrt{h_{t-i}}}\right|+\sum_{k=1}^{r} \gamma_{k} \frac{\varepsilon_{t-k}}{\sqrt{h_{t-k}}}
$$

The EGARCH model has several advantages over the traditional $\mathrm{ARCH}$ and GARCH specifications. First, the variance specification represented in Equation 6 makes it possible to capture the asymmetric effects of good news and bad news on volatility, which is preferable in the context of inflation and inflation uncertainty. Second, since $\log h_{t}$ is modeled, then even in the presence of negative parameters, $h_{t}$ will be positive, thus relieving the nonnegativity constraints artificially imposed on GARCH parameters.

\section{Estimation and Results}

\subsection{Construction of Mean Equation}

Though the initial unit root tests and cointegration analysis show that $\pi_{t}, M 2 G_{t}$ and $R G_{t}$ are stationary and might be cointegrated in the long run, the results are not highly significant and we have equal reason (rejection of null of unit root at $10 \%$ significance level) to formulate a model in the original form of variables instead of their detrended series. We choose to model inflation in autoregressive distributed lag (ADL) form:

$$
\delta(L) \pi_{t}=\lambda+\theta(L) M 2 G_{t}+\varphi(L) R G_{t}+\varepsilon_{t}
$$

Where $\delta(L), \theta(L)$, and $\varphi(L)$ are appropriate lag polynomials of $\pi_{t}, M 2 G_{t}$, and $R G_{t}$ respectively. There is strong evidence that inflation in Pakistan is a 
monetary phenomenon. Qayyum (2006) and Kemal (2006) suggest that excess money supply growth has been a significant contributor to the rise in inflation in Pakistan. Khalid (2005) uses bivariate VAR analysis to conclude that seigniorage and money depth can be considered major determinants of inflation in Pakistan. Ahmad et al. (1991) finds that the major determinants of inflation include lagged inflation and nominal money growth. In an IMF working paper, Schimmelpfennig et al. (2005) has developed three different models to forecast inflation: the univariate model (ARIMA-based), unrestricted VAR model, and leading indicators model (LIM). They found the LIM based on broad money growth, private sector credit growth and lags in inflation worked best for ex-post inflation forecasts in Pakistan. $\pi_{t}$ and $M 2 G_{t}$ have a correlation of 0.23 which increases to $0.29,0.34$ and 0.36 if we take $M 2 G_{t-1}, M 2 G_{t-2}$ and $M 2 G_{t-3}$ respectively instead of $M 2 G_{t}$, which clearly indicates the transmission delay in monetary stance, thus making us more confident about the selection of the ADL model. In this scenario we expect $\theta s$ to be positive and significant.

The bidirectional relationship between inflation and growth is widely accepted. However, according to the classical quantity theory of money, under the assumption of constant velocity and M2 growth, real GDP growth should have a negative impact on inflation. Domac and Elbrit (1998) carried out a cointegration analysis and developed an ECM for Albanian data, finding evidence to support classical supply shocks theory, which shows that growth, through structural reforms and improved infrastructure, can significantly reduce inflation. Handerson (1999), Becker and Gordon (2005), Murphy (2007), and Robert McTeer (2007) are among many who strongly believe that increasing growth leads to the strong impact of inflation in an opposite direction. Recently in 2008, the ECB's and Bundesbank presidents said that, "Slowing growth may not be sufficient to reduce inflation in Eurozone," thus negating the positive relationship between inflation and growth. Therefore, despite obtaining a strong, positive, and significant relationship between $\pi_{t}$ and $R G_{t}$ from the cointegrating regression (Equation 1), we still expect a negative sign for $\varphi s$ in our model explaining the negative impact of supply shocks on inflation, especially with lagged values of $R G_{t}$.

The reason for including an autoregressive term $\delta(L) \pi_{t}$ is straightforward. Inflation, like many other economic variables, has shown strong inertia in various studies. There may be many reasons for this inertia, such as the inability of market agents to interpret and respond in a timely manner after the arrival of a particular announcement or news, or the probability of uncertainty linked to that news, or the overreaction 
of market participants following herd behavior. In case of the presence of strong inflationary inertia, as is evident from many studies, we expect $\delta s$ to be positive and highly significant.

The optimal number of lags is obtained by using Akaike and Schwartz's information criteria (AIC) and BIC. In this case, it is 1, both for the autoregressive term and distributed lag term. Thus, we finalize the ADL $(1,1)$ model to estimate mean inflation.

$$
\pi_{t}=\lambda+\delta_{1} \pi_{t-1}+\theta_{1} M 2 G_{t-1}+\varphi_{1} R G_{t-1}+\varepsilon_{t}
$$

Regression results for Equation 8 are reported in Table-7:

Table-7: Regression Results of ADL $(1,1)$ Model

\begin{tabular}{lc}
\hline Variables & Coefficients \\
\hline$\lambda$ & 0.335 \\
$\delta_{1}$ & $0.898^{* * *}$ \\
$\theta_{1}$ & $0.058^{* *}$ \\
$\varphi_{1}$ & -0.0497 \\
\hline Adjusted R-Square & AIC $=3.41$, \\
0.8103 & BIC $=3.501$ \\
\hline F-Statistic & DW-Stat \\
$176.15^{* * *}$ & 1.588 \\
\hline Breusch-Godfrey Serial Correlation LM Test: & ARCH LM Test: \\
Lag $4=20.13^{* * *}$ & Lag $4=6.24$ \\
\hline
\end{tabular}

Note: ${ }^{* * * * *, *}$ respectively indicates rejection of the null at $1 \%, 5 \%$ and $10 \%$ significance levels.

Due to the presence of significant serial correlation in the residuals of the above model as indicated by the Breusch-Godfrey test and LjungBox Q statistics, we introduce AR (1) and AR (4) error terms in Equation 7. Lag orders of the error term are identified through the partial autocorrelogram function (PAF) of residuals. So the model becomes:

$$
\begin{aligned}
& \pi_{t}=\lambda+\delta_{1} \pi_{t-1}+\theta_{1} M 2 G_{t-1}+\varphi_{1} R G_{t-1}+u_{t} \\
& u_{t}=\rho_{1} u_{t-1}+\rho_{4} u_{t-4}+\varepsilon_{t}
\end{aligned}
$$


Table-8: Results of Equation 9

\begin{tabular}{ll}
\hline Variables & Coefficients \\
\hline$\lambda$ & 0.1303 \\
$\delta_{1}$ & $0.929^{* * *}$ \\
$\theta_{1}$ & $0.051^{* *}$ \\
$\varphi_{1}$ & -0.038 \\
$\rho_{1}$ & $0.168^{*}$ \\
$\rho_{4}$ & $-0.374^{* * *}$ \\
\hline Adjusted R-Square & AIC $=3.203545$, \\
0.850537 & BIC $=3.343$ \\
\hline F-Statistic & DW-Stat \\
$136.44^{* * *}$ & 1.91 \\
\hline Breusch-Godfrey Serial Correlation LM Test: & ARCH LM Test: \\
Lag 4=5.76 & Lag $4=5.14$ \\
\hline
\end{tabular}

Note: $* * * * *, *$ respectively indicates rejection of the null at $1 \%, 5 \%$ and $10 \%$ significance levels.

After introducing AR specification of residuals, we find no evidence of serial correlation in the DW Stat, Breusch-Godfrey test, and Ljung Box Q-Statistics (reported in Table-9). The R-square term also improves by about $4 \%$ due to the inclusion of autoregressive components of errors.

Table-9: Q-Stat Table for Residuals

\begin{tabular}{ccc}
\hline Lag & Q-Stat & Prob. \\
\hline 3 & 0.75 & 0.39 \\
5 & 2.18 & 0.54 \\
10 & 5.13 & 0.74 \\
15 & 14.80 & 0.32 \\
20 & 19.23 & 0.38 \\
25 & 20.99 & 0.58 \\
30 & 22.75 & 0.75 \\
35 & 25.97 & 0.803 \\
\hline
\end{tabular}




\subsection{Estimation of Uncertainty}

As far as the variance equation is concerned, we do find any $\mathrm{ARCH}$ model from $\mathrm{ARCH}(1)$ to $\mathrm{ARCH}(4)$ with significant estimated parameters along with conformity of constraints imposed on $\mathrm{ARCH}(\mathrm{p})$ process. Thus, we decide to opt for GARCH estimation. Table 10 provides the results of two different models.

Table-10: GARCH Estimates of Conditional Variance

\begin{tabular}{|c|c|c|}
\hline & Model 1 & Model 2 \\
\hline \multicolumn{3}{|l|}{ Mean Equation } \\
\hline Variables & GARCH $(1,1)$ & $\operatorname{GARCH}(1,1)$ \\
\hline$\lambda$ & 0.148 & -0.235 \\
\hline$\phi_{1}$ & $0.937^{* * *}$ & $0.936^{* * *}$ \\
\hline$\theta_{1}$ & $0.046^{*}$ & $0.048^{* *}$ \\
\hline$\varphi_{1}$ & -0.031 & \\
\hline$\rho_{1}$ & 0.176 & $0.202^{*}$ \\
\hline$\rho_{4}$ & $-0.411784^{* * *}$ & $-0.419^{* * *}$ \\
\hline \multicolumn{3}{|l|}{ Variance Equation } \\
\hline$\alpha_{Q}$ & $1.645^{* * *}$ & 0.208 \\
\hline$\alpha_{1}$ & $0.235^{*}$ & $0.315^{* * *}$ \\
\hline$\beta_{1}$ & -0.438 & $0.609^{* * *}$ \\
\hline \multicolumn{3}{|l|}{$\gamma$} \\
\hline R-Square & 0.85 & 0.83 \\
\hline DW Stat & 1.93 & 1.69 \\
\hline Akaike criterion & 3.21 & 3.32 \\
\hline Schwarz criterion & 3.424 & 3.501 \\
\hline F-Stat & $82.503^{* * *}$ & $85.387^{* * *}$ \\
\hline
\end{tabular}

Note: $* * *, * *, *$ respectively indicates rejection of the null at $1 \%, 5 \%$ and $10 \%$ significance levels. 


\subsection{Tests for Asymmetries in Volatility}

Engle and $\mathrm{Ng}$ (1993) have devised a set of tests to confirm the asymmetry present in volatility, if any. These tests are generally known as sign and size bias tests. We use these tests to determine whether an asymmetric model is required to capture inflation uncertainty or whether the GARCH model is an adequate model.

We apply the sign and size bias tests to the residuals of GARCH $(1,1)$ (Model 2), whose mean and variance equations are given below.

\section{Mean Equation:}

$$
\begin{aligned}
& \pi_{t}=\lambda+\delta_{1} \pi_{t-1}+\theta_{1} M 2 G_{t-1}+u_{t} \\
& u_{t}=\rho_{1} u_{t-1}+\rho_{4} u_{t-4}+\varepsilon_{t}
\end{aligned}
$$

\section{Variance Equation:}

$$
h_{t}=\alpha_{o}+\sum_{i=1}^{q} \alpha_{i} \varepsilon_{t-i}^{2}+\sum_{j=1}^{p} \beta_{j} h_{t-j}
$$

Where $\alpha_{o}>0, \alpha_{i} \geq 0$ and $i=1,2, \ldots \ldots, q$

$$
\beta_{j} \geq 0 \text { and } j=1,2, \ldots \ldots, p
$$

The test for sign bias is based on the significance or otherwise of $\phi_{1}$ in equation 10.

$$
\begin{aligned}
& \hat{\varepsilon}_{t}^{2}=\phi_{o}+\phi_{1} S_{t-1}^{-}+v_{t} \\
& S_{t-1}^{-} \text {is } 1 \text { if } \varepsilon_{t-1}<0 \text { and } 0 \text { otherwise }
\end{aligned}
$$

Where $v_{t}$ is an iid error term. If positive and negative inflation shocks have different impacts on conditional variance, then $\phi_{1}$ will be statistically significant.

It is most likely, especially in the case of inflation, that the magnitude or size of the inflation shock will have an effect whether or not the response of volatility to a shock is symmetric. Engle and $\mathrm{Ng}$ originally suggested a negative sign bias test, based on a regression where $S_{t-1}^{-}$is 
now used as a slope dummy variable. Negative sign bias is argued to be present if $\phi_{1}$ is statistically significant in Equation 11.

$$
\hat{\varepsilon}_{t}^{2}=\phi_{o}+\phi_{1} S_{t-1}^{-} \varepsilon_{t-1}+v_{t}
$$

However we made little change in that and conducted the above test as positive sign bias test additionally.

$$
\begin{aligned}
& \hat{\varepsilon}_{t}^{2}=\phi_{o}+\phi_{1} S_{t-1}^{+} \varepsilon_{t-1}+v_{t} \\
& S_{t-1}^{\mp} \text { is } 1 \text { if } \varepsilon_{t-1}>0 \text { and } 0 \text { otherwise }
\end{aligned}
$$

Finally setting $S_{t-1}^{+}=1-S_{t-1}^{-}$so that $S_{t-1}^{+}$would become the dummy to capture positive inflation shocks, Engle and $\mathrm{Ng}$ (1993) proposed a joint test for size and sign bias based on following regression:

$$
\hat{\varepsilon}_{t}^{2}=\phi_{o}+\phi_{1} S_{t-1}^{-}+\phi_{2} S_{t-1}^{-} \varepsilon_{t-1}+\phi_{3} S_{t-1}^{+} \varepsilon_{t-1}+v_{t}
$$

The significant value of $\phi_{1}$ in Equation 13 indicates the presence of sign bias, i.e., positive and negative inflation shocks have different impacts on future uncertainty. On the other hand, significant values of $\phi_{2}$ and $\phi_{3}$ suggest the presence of size bias, where both the sign and magnitude of shock are important. A joint test statistic is $T R^{2}$ which will asymptotically follow a $\chi^{2}$ distribution with three degrees of freedom under the null hypothesis of no asymmetric effects.

\section{Table-11: Tests for Asymmetries in Volatility}

\begin{tabular}{lcccc}
\hline & $\begin{array}{c}\text { Sign Bias } \\
\text { Test } \\
\text { Eq. 10 }\end{array}$ & $\begin{array}{c}\text { Negative Sign } \\
\text { Bias Test } \\
\text { Eq. 11 }\end{array}$ & $\begin{array}{c}\text { Positive Sign } \\
\text { Bias Test } \\
\text { Eq. 12 }\end{array}$ & $\begin{array}{c}\text { Joint test for Sign } \\
\text { and Size Bias } \\
\text { Eq. 13 }\end{array}$ \\
\hline$\phi_{0}$ & $1.901^{* * *}$ & $1.68^{* * *}$ & $1.001^{* * *}$ & 0.48 \\
$\phi_{1}$ & -0.66 & 0.22 & $1.23^{* * *}$ & 0.56 \\
$\phi_{2}$ & & & & -0.23 \\
$\phi_{3}$ & & & & $1.57^{* * *}$ \\
$T R^{2}$ & & & & $8.92^{* *}$ \\
\hline
\end{tabular}

The individual regression results of the sign bias test and negative sign bias test does not reveal any evidence of asymmetry as the value of $\phi_{1}$ is insignificant. But we can see that the coefficient indicating positive sign bias is significant in individual as well as joint tests. Although none 
of the other coefficients except $\phi_{2}$ are significant in the joint regression, the $\chi^{2}$ test statistic is significant at $5 \%$, suggesting a rejection of the null hypothesis of no asymmetries.

The above results lead us to opt for asymmetric GARCH models instead of symmetric and in Table-12 we report the results of three asymmetric GARCH models.

Table-12: GJR-GARCH and EGARCH Estimations of Conditional Variance

\begin{tabular}{llll}
\hline & Model 3 & Model 4 & Model 5 \\
\hline Variables & GJR-GARCH & GJR-GARCH & EGARCH \\
\hline $\boldsymbol{\lambda}$ & -0.024 & -0.237 & 0.066 \\
$\boldsymbol{\delta}_{\mathbf{1}}$ & $0.913^{* * *}$ & $0.914^{* * *}$ & $0.917^{* * *}$ \\
$\boldsymbol{\theta}_{\mathbf{1}}$ & $0.064^{* *}$ & 0.063 & $0.054^{* * *}$ \\
$\boldsymbol{\rho}_{\mathbf{1}}$ & -0.0301 & & $-0.036^{*}$ \\
$\boldsymbol{\rho}_{\mathbf{1}}$ & $0.204^{* *}$ & 0.188 & $0.161^{* * *}$ \\
$\boldsymbol{\rho}_{\mathbf{4}}$ & $-0.425^{* * *}$ & $-0.339855^{* *}$ & $-0.402^{* * *}$ \\
$\boldsymbol{\lambda}$ & $0.415^{*}$ & 1.437 & 0.22 \\
$\boldsymbol{\delta}_{\mathbf{1}}$ & 0.071 & 0.078 & $0.265^{* * *}$ \\
$\boldsymbol{\theta}_{\mathbf{1}}$ & $0.672^{* * *}$ & 0.478 & $-0.954^{* * *}$ \\
$\boldsymbol{\rho}_{\mathbf{1}}$ & -0.151 & $-0.293^{* *}$ & $0.14^{* *}$ \\
$\mathbf{R}-S q u a r e$ & 0.84 & 0.83 & 0.843 \\
$\begin{array}{l}\text { DW Stat } \\
\text { Akaike } \\
\text { criterion }\end{array}$ & 1.93 & 1.65 & 1.844 \\
$\begin{array}{l}\text { Schwarz } \\
\text { criterion }\end{array}$ & 3.22 & 3.49 & 3.16 \\
F-Stat & $71.5^{* * *}$ & 3.7 & 3.4 \\
\hline
\end{tabular}

Note: $* * * * *, *$ respectively indicates rejection of the null at $1 \%, 5 \%$ and $10 \%$ significance levels.

Results from GJR-GARH (Models 3 and 4) confirm that these models are successful in modeling the asymmetric (leverage) effects of lagged inflation shocks on one period ahead of conditional variance. From both models, we obtain the negative values of $\gamma$ as expected, thus 
concluding that negative inflation shocks (good news) reduce inflation uncertainty. On the other hand, the value of $\gamma$ is positive and significant in EGARCH estimation (Model 5) suggesting that when there is an unexpected increase in inflation, resulting in positive inflation shocks (bad news), inflation uncertainty increases more than when there is an unanticipated decrease in inflation.

\subsection{News Impact Curves}

To further investigate the asymmetric behavior of inflation uncertainty, we have analyzed the effect of news on volatility or inflation uncertainty with the help of news impact curves. By keeping constant all the information at $\mathrm{t}-2$ and earlier, we can examine the implied relation between $\varepsilon_{t-1}$ and $h_{t}$ which we called a news impact curve. This is a pictorial representation of the degree of asymmetry of volatility to positive and negative shocks and it plots the next period uncertainty $h_{t}$ that will arise from various positive and negative values (news) of past inflation shocks $\left(\varepsilon_{t-1}\right)$ (Pagan and Schwert, 1990). For the GARCH model, this curve is a quadratic function centered at $\varepsilon_{t-1}=0$.. Equations for the news impact curve for the GARCH, GJR-GARCH and EGARCH models are provided in Table-13.

Table-13: News Impact Curve for different GARCH processes

\begin{tabular}{|c|c|}
\hline $\operatorname{GARCH}(\mathbf{1}, \mathbf{1})$ & $\begin{array}{c}h_{t}=A+\alpha_{1} \varepsilon_{t-1}^{2} \\
\text { Where } A=\alpha_{o}+\beta_{1} \bar{\sigma}^{2} \\
\text { And } \bar{\sigma}^{2}=\alpha_{o} /\left[1-\alpha_{1}-\beta_{1}\right]\end{array}$ \\
\hline $\begin{array}{l}\text { GJR-GARCH(1,1) } \\
\text { Or } \\
\operatorname{TGARCH}(1,1)\end{array}$ & $\begin{array}{c}h_{t}=A+\left(\alpha_{1}+\gamma_{1} I_{t-1}\right) \varepsilon_{t-1}^{2} \\
\text { Where } A=\alpha_{o}+\beta_{1} \bar{\sigma}^{2} \\
\text { And } \bar{\sigma}^{2}=\alpha_{o} /\left[1-\alpha_{1}-\beta_{1}-\left(\frac{\gamma_{1}}{2}\right)\right]\end{array}$ \\
\hline EGARCH(1,1) & $\begin{array}{c}h_{t}=A \exp \left\{\frac{\alpha_{1}\left(\left|\varepsilon_{t-1}\right|+\gamma_{1} \varepsilon_{t-1}\right)}{\bar{\sigma}}\right\} \\
\text { Where } A=\bar{\sigma}^{2 \beta_{1}} \exp \left\{\alpha_{o}\right\} \\
\bar{\sigma}^{2}=\exp \left\{\frac{\alpha_{o}+\alpha_{1} \sqrt{2 / \pi}}{1-\beta_{1}}\right\}\end{array}$ \\
\hline
\end{tabular}

Source: Eric Zevot (2008), "Practical Issues in the Analysis of Univariate GARCH Models". 
Where $h_{t}$ is the conditional variance at time $\mathrm{t}, \varepsilon_{t-1}$ is the inflation shock at time $\mathrm{t}-1, \bar{\sigma}$ is the unconditional standard deviation of inflation shocks, $\alpha_{o}$ and $\beta_{1}$ are the constant term and parameter corresponding to $h_{t-1}$ in GARCH variance equation respectively.

The resulting news impact curves for GARCH, GJR-GARCH and EGARCH models are given in Figure-5.
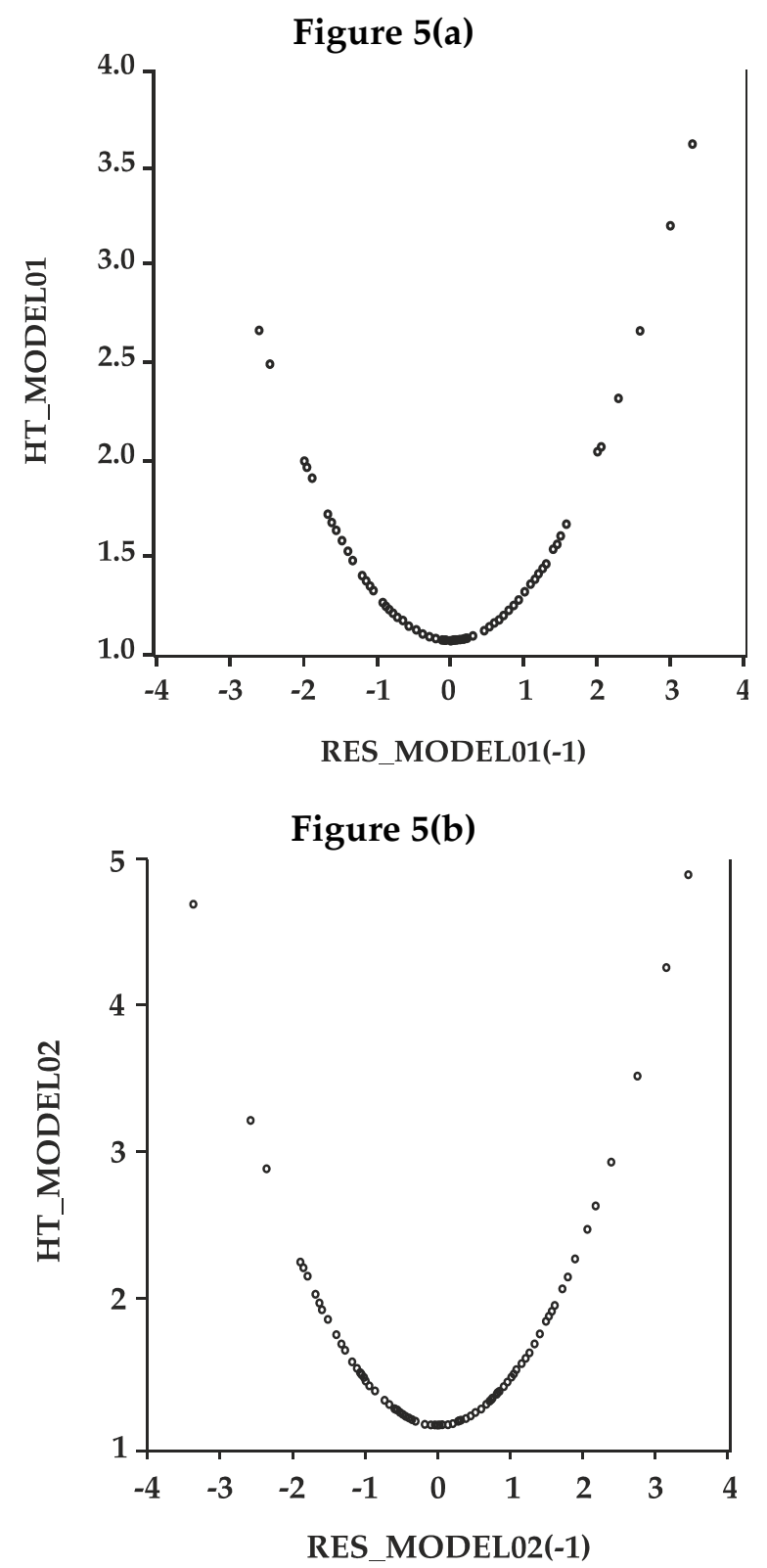
It can be seen in Figures 5(a) and 5(b), that the GARCH news impact curves are symmetrical at about zero, so that a shock of given magnitude will have the same impact on future volatility, irrespective of its sign. On the other hand GJR news impact curves (Figures 5(c) and $5(\mathrm{~d})$ ) are asymmetric where negative inflation shocks reduce future volatility exactly as was described in Equation 5.
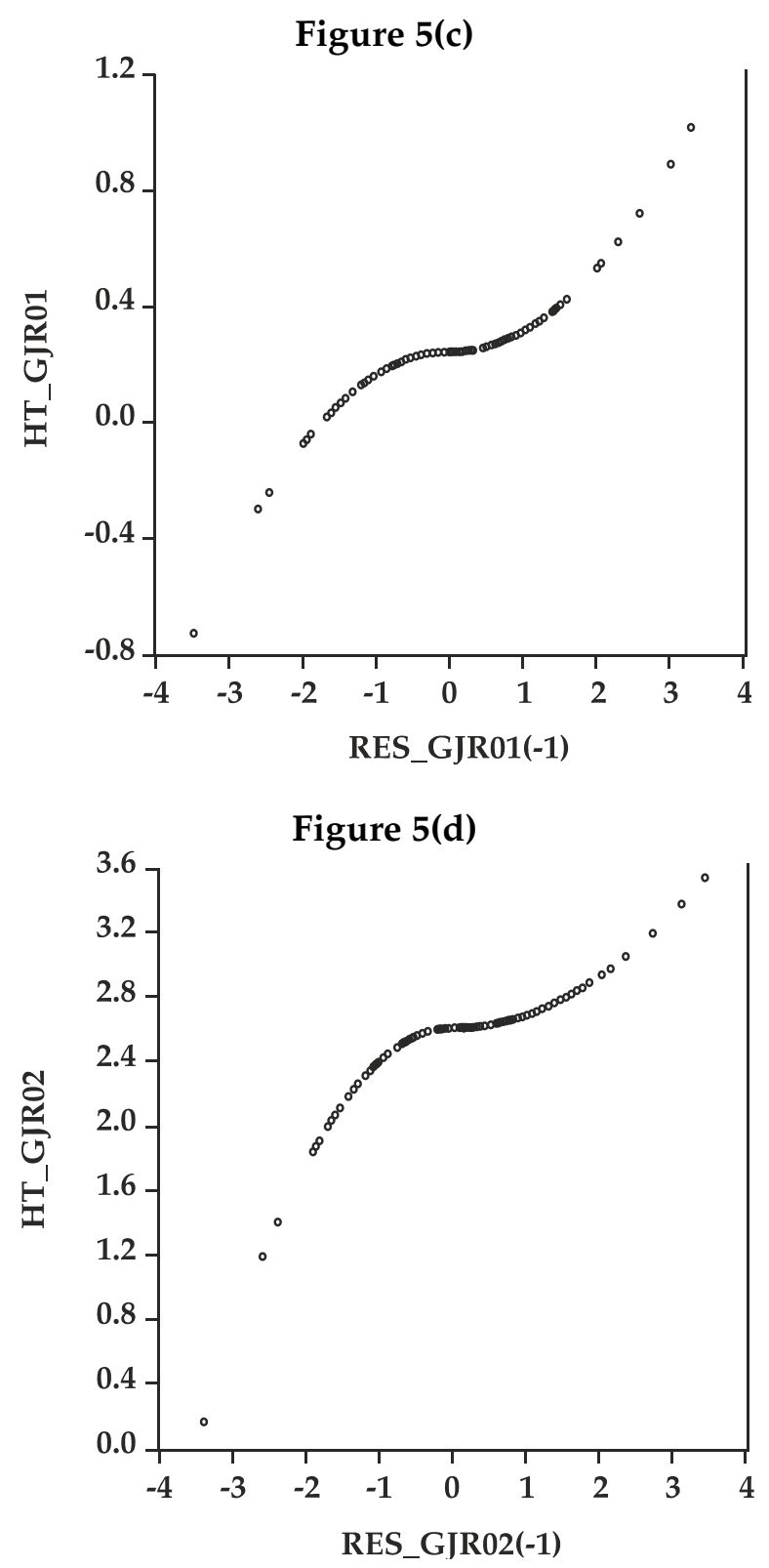


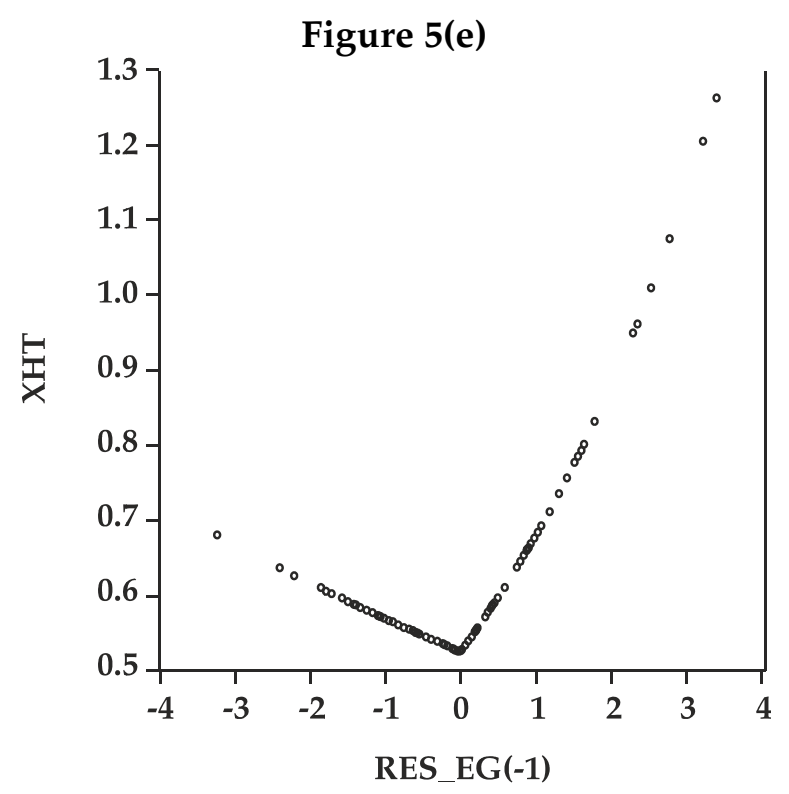

Figure 5(e) is also in accordance with our expectations; we see that an unexpected increase in inflation (positive inflation shocks) increases volatility more than when there is a decrease in inflation, that is, what we can also interpret from the positive and significant value of $\gamma$ reported for the EGARCH model in Table-12.

\subsection{Testing of Friedman-Ball Hypothesis (Granger Causality)}

In order to assess the Friedman-Ball and Cukierman-Meltzer hypotheses, we implement the bivariate Granger causality test up to 10 lags, between inflation and inflation uncertainty (one period ahead of conditional forecast of variance) derived from models 1 to 5 . The results for the GARCH models (models 1 and 2) are reported in Table-14(a). We report only $p$-values for Wald statistics for the null hypothesis that inflation does not cause uncertainty in the first column and that uncertainty does not cause inflation in the second column for each model. The results reported in Table-14(a) are not very encouraging and reject both the Friedman-Ball and Cukierman-Meltzer hypotheses. It appears that neither inflation nor inflation uncertainty causes the other. 
Table-14(a): Granger Causality Test (P-values of Wald Statistics)

\begin{tabular}{lcccc}
\hline \multirow{2}{*}{ Lags } & \multicolumn{2}{c}{ GARCH (Model 01) } & \multicolumn{2}{c}{ GARCH (Model 02) } \\
\cline { 2 - 5 } & $\begin{array}{c}\boldsymbol{\pi} \text { does not } \\
\text { cause } \boldsymbol{h}_{t}\end{array}$ & $\begin{array}{c}\boldsymbol{h}_{t} \text { does not } \\
\text { cause } \boldsymbol{\pi}\end{array}$ & $\begin{array}{c}\boldsymbol{\pi} \text { does not } \\
\text { cause } \boldsymbol{h}_{t}\end{array}$ & $\begin{array}{c}\boldsymbol{h}_{t} \text { does not } \\
\text { cause } \boldsymbol{\pi}\end{array}$ \\
\hline 1 & 0.269 & 0.726 & 0.089 & 0.620 \\
2 & 0.565 & 0.256 & 0.077 & 0.725 \\
3 & 0.734 & 0.390 & 0.189 & 0.518 \\
4 & 0.642 & 0.464 & 0.092 & 0.296 \\
5 & 0.915 & 0.301 & 0.171 & 0.125 \\
6 & 0.951 & 0.127 & 0.295 & 0.104 \\
7 & 0.484 & 0.188 & 0.428 & 0.210 \\
8 & 0.619 & 0.370 & 0.452 & 0.180 \\
9 & 0.423 & 0.532 & 0.317 & 0.213 \\
10 & 0.436 & 0.317 & 0.374 & 0.211 \\
\hline
\end{tabular}

However, the results reported in Table-14(b) for GJR-GARCH (models 3 and 4) and EGARCH (model 5) are consistent and strongly reject the null that inflation does not cause uncertainty, thus supporting the Friedman-Ball hypothesis.

Table-14(b): Granger Causality Test (P-values of Wald Statistics)

\begin{tabular}{|c|c|c|c|c|c|c|}
\hline \multirow{2}{*}{ Lags } & \multicolumn{2}{|c|}{$\begin{array}{l}\text { GJR-GARCH } \\
\text { (Model 03) }\end{array}$} & \multicolumn{2}{|c|}{$\begin{array}{l}\text { GJR-GARCH } \\
\text { (Model 04) }\end{array}$} & \multicolumn{2}{|c|}{$\begin{array}{c}\text { EGARCH } \\
\text { (Model 05) }\end{array}$} \\
\hline & $\begin{array}{l}\pi \text { does not } \\
\text { cause } \boldsymbol{h}_{t}\end{array}$ & $\begin{array}{c}\boldsymbol{h}_{t} \text { does not } \\
\text { cause } \pi\end{array}$ & $\begin{array}{c}\pi \text { does not } \\
\text { cause } \boldsymbol{h}_{t}\end{array}$ & $\begin{array}{c}\boldsymbol{h}_{t} \text { does not } \\
\text { cause } \pi\end{array}$ & $\begin{array}{l}\pi \text { does not } \\
\text { cause } \boldsymbol{h}_{t}\end{array}$ & $\begin{array}{c}\boldsymbol{h}_{t} \text { does not } \\
\text { cause } \pi\end{array}$ \\
\hline 1 & 2.6E-05 & 0.418 & 0.004 & 0.634 & 0.001 & 0.074 \\
\hline 2 & 2.2E-25 & 0.846 & 3.0E-17 & 0.544 & 9.9E-08 & 0.025 \\
\hline 3 & 4.3E-27 & 0.841 & 7.4E-20 & 0.175 & $1.5 \mathrm{E}-08$ & 0.071 \\
\hline 4 & 1.3E-27 & 0.001 & $9.4 \mathrm{E}-24$ & 0.086 & $1.2 \mathrm{E}-08$ & 0.004 \\
\hline 5 & 6.7E-33 & 0.948 & $1.2 \mathrm{E}-25$ & 0.9998 & 4.9E-08 & 0.277 \\
\hline 6 & $1.5 \mathrm{E}-35$ & 0.393 & 4.7E-26 & 0.858 & 2.1E-09 & 0.527 \\
\hline 7 & $1.4 \mathrm{E}-33$ & 0.084 & $2.5 \mathrm{E}-25$ & 0.691 & 7.5E-08 & 0.177 \\
\hline 8 & 1.7E-32 & 0.185 & $1.2 \mathrm{E}-23$ & 0.081 & $1.4 \mathrm{E}-07$ & 0.214 \\
\hline 9 & $1.4 \mathrm{E}-30$ & 0.029 & $1.3 \mathrm{E}-22$ & 0.166 & 3.7E-06 & 0.451 \\
\hline 10 & 9.3E-32 & 0.12 & $1.6 \mathrm{E}-23$ & 0.339 & 1.3E-05 & 0.456 \\
\hline
\end{tabular}




\section{Policy Implications}

The above analysis provides many insights for policymakers regarding inflation and inflation uncertainty. Most important is the recognition of asymmetric behavior in inflation uncertainty, which is captured by the GJR-GARCH and EGARCH models and can be viewed with the help of corresponding news impact curves (Figures $5 c$ to 5e). This identification of asymmetry is extremely important for monetary authorities and highlights the importance of inflation stabilization programs or inflation targeting policies, which, if successful in reducing the inflation level, could eventually reduce the next period price volatility (Jonhson, 2002). It is also worth noting that both asymmetric specifications (GJR-GARCH and EGARCH) strongly support the Friedman-Ball hypothesis, leading us to believe that higher inflation rates lead to a higher level of uncertainty, which could negatively affect the economy through financial markets, decision variables, and productive vs. protective strategy channels, thus potentially curbing real economic activity. However, as mentioned earlier, the successful implementation of inflation stabilization programs can equally reduce the next period uncertainty due to the presence of causality running between inflation and inflation uncertainty (Friedman-Ball hypothesis).

The strong rejection of the Cukierman-Meltzer hypothesis implicitly rejects the so-called stabilizing hypothesis by Holland (1995), which says that high inflation uncertainty can have a negative causal impact on succeeding average inflation rates because the natural stance of policymakers, in the presence of high inflation and high uncertainty, would be to contract the growth of the money supply, which could reduce average inflation rates in upcoming periods. This should draw the attention of policymakers, especially in the context of Pakistan. We have already established that, because of the simultaneous existence of asymmetry and causality running from inflation to inflation uncertainty, Pakistan strongly needs stabilization programs to keep the welfare cost of inflation as low as possible by curbing inflation when there is higher inflation uncertainty. So far, Pakistan has implemented few such programs. However the straightforward rejection of the CukiermanMeltzer hypothesis (causality running from uncertainty to inflation) identifies the inability and/or unsuccessful implementation of such programs, which should have been considered seriously by monetary authorities in Pakistan since these programs are very costly to the economy by default. 


\section{Conclusion}

This study provides several interesting results. First, we have estimated inflation uncertainty as a time varying conditional variance of inflation shocks and found that asymmetric GARCH models (GJRGARCH and EGARCH) perform better than simple GARCH models. GJR-GARCH estimates the negative and significant value of the leverage effect parameter, which suggests that the negative shock of inflation tends to decrease next period uncertainty; this conclusion is also supported by the results of the EGARCH models. Second, news impact curves graphically reflect the asymmetric behavior of inflation uncertainty from GJR-GARCH and EGARCH models. Finally, the bivariate Granger causality test strongly supports the Friedman-Ball hypothesis for GJRGARCH and EGARCH models, i.e., high inflation causes inflation uncertainty and the causality runs from inflation to inflation uncertainty. We do not find any evidence in support of the Cukierman-Meltzer hypothesis. 


\section{References}

Andersen, T.G., and Bollerslev, T. (2006). Volatility and Correlation Forecasting. Handbook of Economic Forecasting, 1.

Apergis, N. (2006). Inflation, Output Growth, Volatility and Causality: Evidence from Panel Data and G7 Countries. Economic Letters, 83, 185-191.

Ball, L. (1992). How does Inflation Raise Inflation Uncertainty? Journal of Monetary Economics, 29, 371-388.

Berument, H. et al. (2001). Modeling Inflation Uncertainty using EGARCH: An Application to Turkey. Bilkent University Discussion Paper.

Bilquees, F. (1988). Inflation in Pakistan: Empirical Evidence on the Monetarist and Structuralist Hypotheses. Pakistan Development Review, 27 (2), 109-130.

Bollerslev, T. (1986). Generalized Autoregressive Conditional Heteroscedasticity. Journal of Econometrics, 31, 307-327.

Bollerslev, T., and Wooldridge, J.M. (1992). Quasi-Maximum Likelihood Estimation and Inference in Dynamic Models with Time-Varying Covariances. Econometric Review, 11, 143-172.

Bokil, M., and Schimmelpfennig, A. (2005). Three Attempts at Inflation Forecasting in Pakistan. IMF Working Paper, WP/05/105.

Bordes, C. et al. (2007). Money and Uncertainty in the Philippines: A Friedmanite Perspective. Conference paper, Asia-Link Program.

Bordes, C., and Maveyraud, S. (2008). The Friedman's and Mishkin's Hypotheses (re)considered. Unpublished.

Brunner, A. D., and Hess, G.D. (1993). Are Higher Levels of Inflation less Predictable? A State-Dependent Conditional Heteroscedasticity Approach. Journal of Business and Economic Statistics, 11 (2), 187-197.

Brunner, A.D., and Simon, D.P. (1996). Excess Returns and Risk at the Long End of the Treasury Market: An EGARCH-M Approach. Journal of Financial Research, 14 (1), 443-457. 
Caporale, T., and McKiernan, B. (1997). High and Variable Inflation: Further Evidence on the Friedman Hypothesis. Economic Letters, 54, 65-68.

Chaudhary, M.A., and Ahmad, N. (1996). Sources and Impacts of Inflation in Pakistan. Pakistan Economic and Social Review, 34 (1), 21-39.

Cheem, N. (2003). Quarterly Growth Rates. Statistics Singapore Newsletter.

Cosimano, T., and Dennis, J. (1988). Estimation of the Variance of US Inflation based upon the ARCH Model. Journal of Money, Credit, and Banking, 20 (3), 409-423.

Crowford, A., and Kasumovich, M. (1996). Does Inflation Uncertainty Vary with the Level Of Inflation? Ottawa: Bank of Canada.

Engle, R. (1982). Autoregressive Conditional Heteroscedasticity with Estimates of United Kingdom Inflation. Econometrica, 987-1007.

Fountas, S. et al. (2000). A GARCH Model of Inflation and Inflation Uncertainty with Simultaneous Feedback. Working Paper.

Fountas, S. et al. (2006). Inflation Uncertainty, Output Growth Uncertainty and Macroeconomic Performance. Oxford Bulletin of Economics and Statistics, 68 (3).

Franses, P.H. (1990). Testing for Seasonal Unit Roots in Monthly Data. Econometric Institute Report No. 9032A. Rotterdam: Erasmus University.

Friedman, M. (1977). Nobel Lecture: Inflation and Unemployment. Journal of Political Economy, 85, 451-472.

Glosten, L. R., Jagannathan, R., and Runkle, D. (1993). On the Relations between the Expected Value and the Volatility of the Normal Excess Return on Stocks. Journal of Finance, 48, 1779-1801.

Golob, J.E. (1994). Does Inflation Uncertainty Increase with Inflation? Federal Reserve Bank of Kansas City Economic Review, Third Quarter.

Grier, K., and Perry, M. (2000). The Effects of Real and Nominal Uncertainty on Inflation and Output Growth: Some GARCH-M Evidence. Journal of Applied Econometrics, 15, 45-48. 
Holland, A.S. (1984). Does Higher Inflation Lead to More Uncertain Inflation? Federal Reserve Bank of St. Louis Review, 66, 15-26.

Hafer, R.W. (1985). Inflation Uncertainty and a Test of the Friedman Hypothesis. Federal Reserve Bank of St. Louis Working Paper 1985-006A.

Hu, M.Y., Jiang, C.X., and Tsoukalas, C. (1997). The European Exchange Rates before and after the Establishment of the European Monetary System. Journal of International Financial Markets, Institutions and Money, 7, 235-253.

Khalid, A. M. (2005). Economic Growth, Inflation and Monetary Policy in Pakistan: Preliminary Empirical Estimates. Pakistan Development Review, 44 (4) Part II, 961-974.

Khan, M.S., and Senhadji, S.A. (2001). Threshold Effects in the Relationship between Inflation and Growth. IMF Staff Papers 48 (1).

Khan, A.H., and Qasim, M.A. (1996). Inflation in Pakistan Revisited. Pakistan Development Review, 35 (4), 747-759.

Khan, M.S., and Schimmelpfennig, A. (2006). Inflation in Pakistan: Money or Wheat? IMF Working Paper, wp/06/60.

Koutmos, G., and Booth, G.G. (1995). Asymmetric Volatility Transmission in International Stock Markets. Journal of International Money and Finance, 14, 747-762.

Malik, W.S., and Ahmad, A.M. (2007). The Taylor Rule and Macroeconomic Performance in Pakistan. Pakistan Development Review, 34.

Malik, W.S. (2006). Money, Output and Inflation: Evidence from Pakistan. Pakistan Development Review, 46 (4).

Nas, T.F., and Perry, M.J. (2000). Inflation, Inflation Uncertainty and Monetary Policy in Turkey. Contemporary Economic Policy, 18, 170180.

Nelson, D.B. (1991). Conditional Heteroscedasticity in Asset Returns: A New Approach. Econometrica, 59, 347-370. 
Price, S., and Nasim, A. (1999). Modeling Inflation and the Demand for Money in Pakistan: Cointegration and the Causal Structure. Economic Modeling, 16, 87-103.

Thornton, J. (2006). High and Variable Inflation: Further Evidence on the Friedman Hypothesis. Southern African Journal of Economics, 74, 167-171.

Tse, Y., \& Booth, G.G. (1996). Common Volatility and Volatility Spillovers between US and Eurodollar Interest Rates: Evidence from the Features Market. Journal of Economics and Business, 48, 299-312.

Qayyum, A. (2006). Money, Inflation and Growth in Pakistan. Pakistan Development Review, 45 (2), 203-212.

Zivot, E. (2008). Practical Issues in the Analysis of Univariate GARCH Models. Unpublished Manuscript. 


\section{Appendix}

Figure 6: Forecast of Conditional Variance (Inflation Uncertainty)
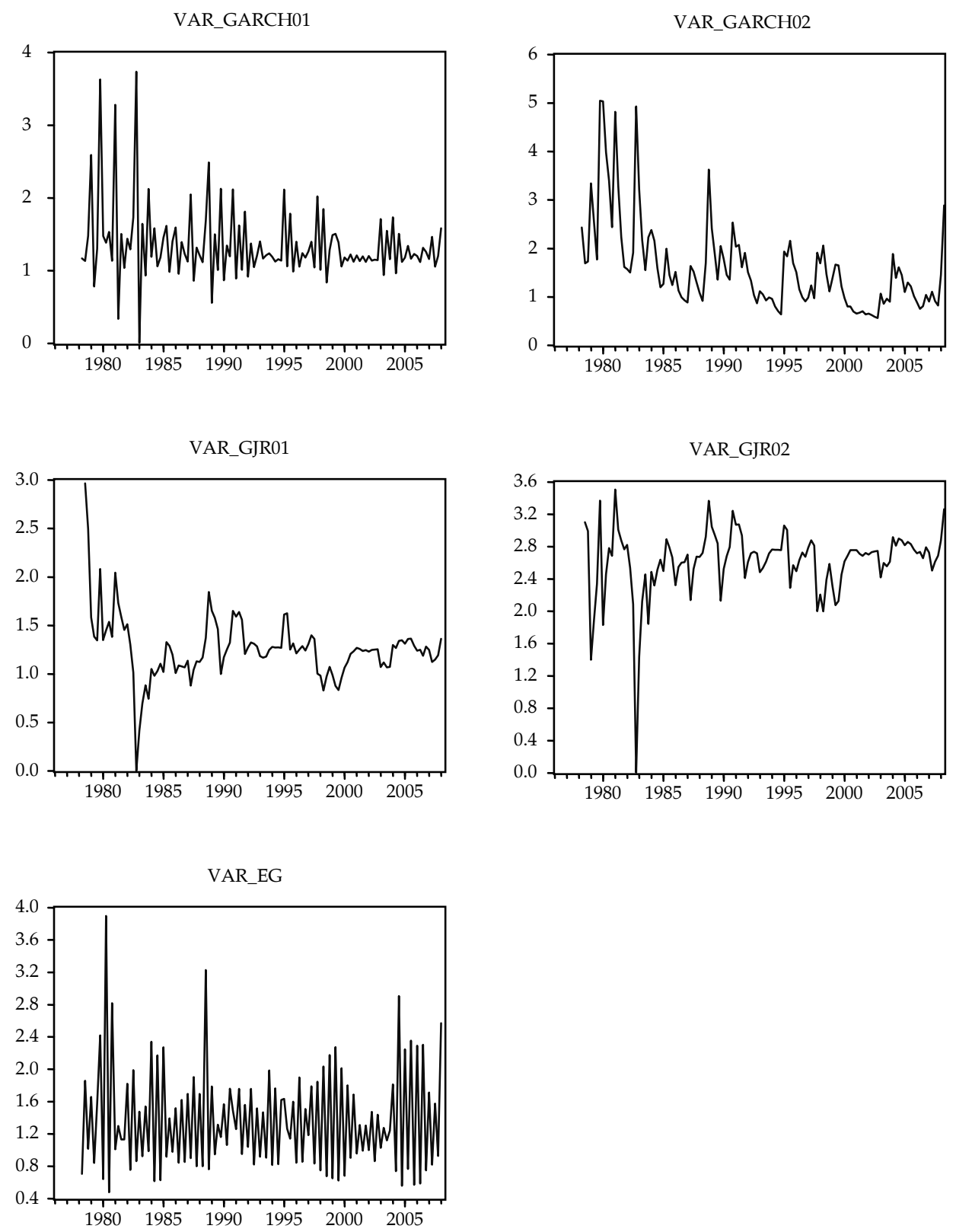


\section{Figure 7: Impulse Response Functions of Uncertainty to Inflation}

Response to Cholesky One S.D. Innovations \pm 2.S.E.

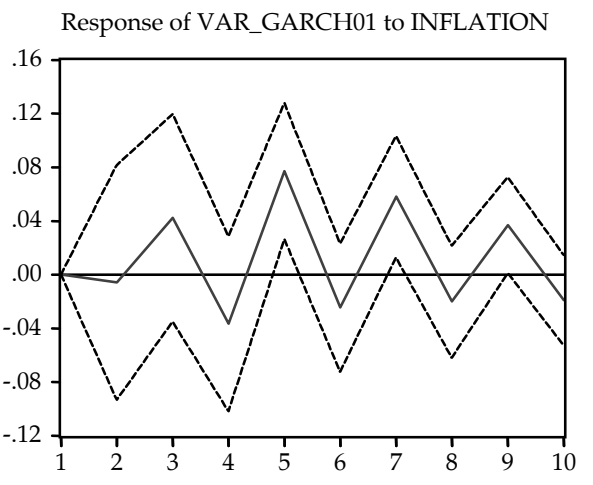

Response of VAR_GARCH02 to INFLATION
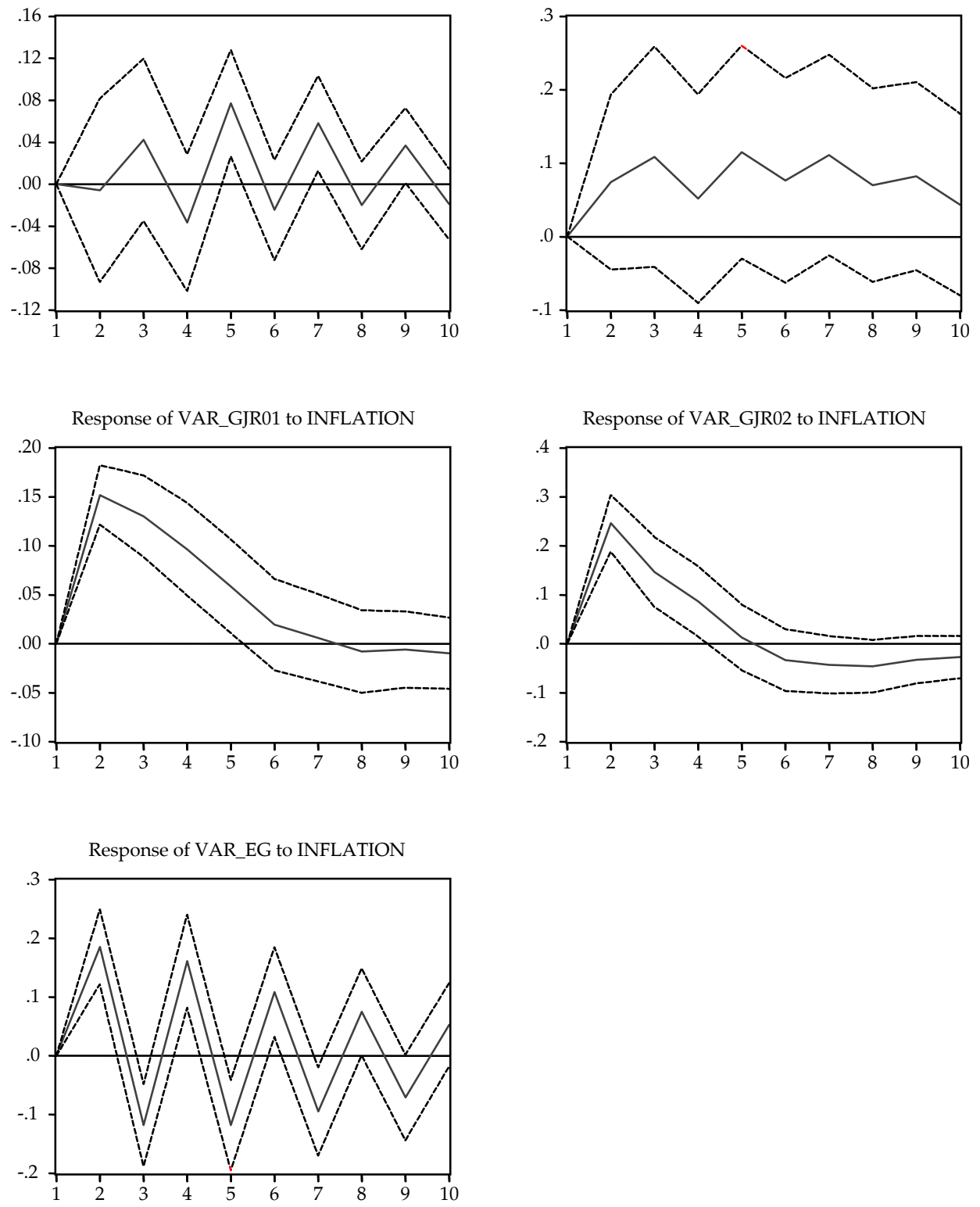